\title{
DETERMINATION OF STRAIN AND STRESS FIELDS IN WELDED JOINTS OF S960-QC STEEL
}

The paper presents the results of two butt welded joints by conventional method. The welding process was performed using a variety of linear welding energy. The studies included experimental and computational part. In experimental studies determined the distribution of hardness and mechanical properties of the individual analyzed sections of welded joints. The data obtained were intended to determine the extent of zones in the welded joints that have certain strength characteristics. Also conducted uniaxial tensile tests of welded joints with the registration of displacement fields on the surface of specimens by means of Aramis video-system what the final result are images of strain fields map on the surface of welded joints. The resulting strain values were compared with the results of numerical computations FEM.

Keywords: Welded joints, strain distributions, strength characteristics, FEM

\section{Introduction}

Recently, more and more are used steels of higher strength characteristics, what translates into improved technical and economic conditions of produced machinery, motor vehicles consisting of a considerable weight reduction while maintaining adequate strength [1]. High-strength steels also apply in the pipelines of high pressure, jib cranes, mining industry. A significant part of the made constructions requires permanent connection of its individual parts, and therefore an important aspect has weldability of these steels. During welding of high-strength steel, on the quality and durability of joints a significant influence has an adopted welding method and also the level of linear energy used while welding [2-6].

With the development of technology on the market, there are new methods to assess the strength of structural elements. One such tool is the optical video-system Aramis by GOM which made possible for the map of strain fields determine. This paper presents the results of experimental research, based on which developed a numerical model for the welded joints strength assessment. The results of numerical simulation of loading the welded joints were compared with the data recorded during the tested specimens using the Aramis video-system.

\section{Tested material and strength characteristics}

The objects of the study are the butt welded joints, in which the base material is a high strength tempered martensite steel S960-QC. The chemical composition and mechanical properties of S960-QC steel are shown in Table 1 and Table 2.

Welding process was performed on steel sheets of $8 \mathrm{~mm}$ thickness by the conventional method using linear welding energy (LWE), respectively, of $1.2 \mathrm{~kJ} / \mathrm{mm}$ and $0.7 \mathrm{~kJ} / \mathrm{mm}$ [3].

Chemical composition (in mass \%) [7]

\begin{tabular}{|c|c|c|c|c|c|c|c|c|c|c|c|}
\hline & $\mathbf{C}$ & Si & Mn & $\mathbf{P}$ & $\mathrm{S}$ & $\mathbf{T i}$ & $\mathbf{C r}$ & Ni & Mo & $\mathbf{V}$ & $\mathbf{C u}$ \\
\hline S960-QC & 0.11 & 0.25 & 1.20 & 0.020 & 0.010 & 0.07 & \multicolumn{5}{|c|}{$\mathrm{CEV}=\mathrm{C}+\mathrm{Mn} / 6+(\mathrm{Cr}+\mathrm{Mo}+\mathrm{V}) / 5+(\mathrm{Cu}+\mathrm{Ni}) / 15$} \\
\hline
\end{tabular}

Mechanical properties and hardness of S960-QC steel [7]

\begin{tabular}{|c|c|c|c|c|}
\hline \hline S960-QC steel & $\boldsymbol{R}_{\boldsymbol{p 0 . 2}}[\mathbf{M P a}]$ & $\boldsymbol{R}_{\boldsymbol{m}}[\mathbf{M P a}]$ & $\boldsymbol{A}_{\mathbf{5}}[\mathbf{\%}]$ & $\mathbf{H V 1 0}$ \\
\hline Data specified according to attest & $\geq 960$ & $\geq 1000$ & $\geq 7$ & $\geq 350$ \\
\hline Data of tests & 1005 & 1090 & 11 & $\sim 365$ \\
\hline
\end{tabular}

\footnotetext{
* KIELCE UNIVERSITY OF TECHNOLOGY, 7 TYSIĄCLECIA PANSTWA POLSKIEGO AV., 25-314 KIELCE, POLAND

* Corresponding author: tpala@tu.kielce.pl
} 
Butt joints were tested for the use of an additional material. The joints were made directly by the manufacturer Ruukki (Finland). In the article presented the results of the research carried out on the provided joints.

Hardness measurements of welded joints were performed in cross-sections. This was to precisely determine hardness values of particular zones and their range in the welded joints. Hardness was measured according to Vicker's method at a load of $10 \mathrm{~N}$ in accordance with the standard EN ISO 9015-1. The measurement was carried out along three measurement lines, located in the middle of the thickness of joints and at distance of $1 \mathrm{~mm}$ from the side of the face and the root of the weld. The results of hardness distribution for the joints presented in the Fig. 1a,b.

The mechanical properties were determined during tested flat specimens of dimensions $2 \times 4 \mathrm{~mm}^{2}$ in cross-section, which were cut from corresponding zones of the welded joint along longitudinal direction of the joints. The cutting process was carried out using high-pressure water-jet stream.

An important feature of the technology used is the lack of thermal impact and narrow cutting slit, which allows made a greater number of specimens from the joint.

Exemplary cutting slits in the joint presented in the (Fig. 2a). So cut specimens were additionally milling machine and prepared to perform the uniaxial tensile test (Fig. 2b).

The tensile load curves and mechanical material properties were determined on the upgraded testing machine UTS-100, equipped with an automated system control and recording the results. The EN ISO 5178 standard is used to determine the strength characteristics of a welded joint material. However, in order to determine the strength characteristics in all joint zones, especially in the HAZ, were made the flat samples shown in Fig. 2. Tests carried out on flat samples in accordance with EN ISO 6892 have determined the strength characteristics in the middle part and at the fusion line in the weld material and in several HAZ zones. Prior to testing, on both sides of the specimens was measured hardness, in order to precisely determine the member- a)
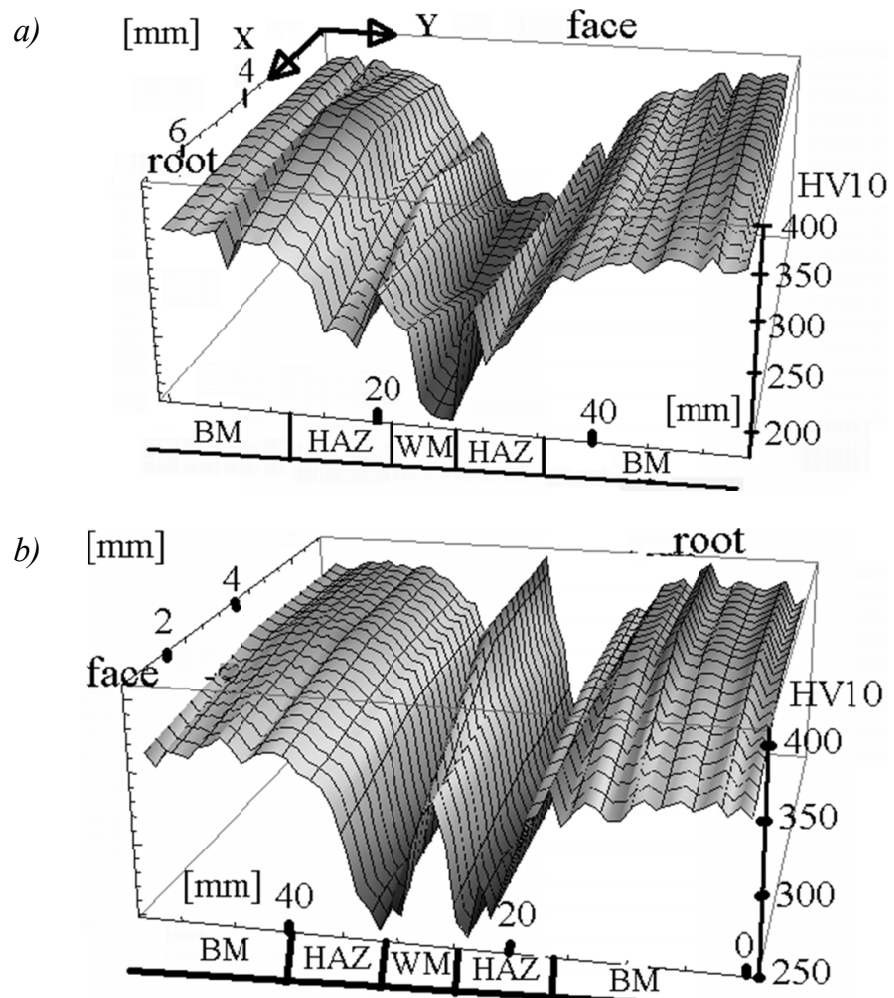

Fig. 1. Hardness distribution in welded joints by LWE means: a) $1.2 \mathrm{~kJ} / \mathrm{mm}$; b) $0.7 \mathrm{~kJ} / \mathrm{mm}$

ship of a given specimen to the corresponded joint zone. During the specimens tested recorded signals of load, $P$, and extensions of the measuring part specimen, $u$, at time. The result of performed tests was to obtain the true stress-strain curves, which are presented until achieving the maximum force (Fig. 3a,b).

Tensile curves indicated in the pictures, as WM corresponds to the specimens cut from the weld material, while BM corresponds to the specimens cut from the base material. Notes (I-VI) corresponds to the specimens taken from the fusion line and heat affected zone, HAZ. a)

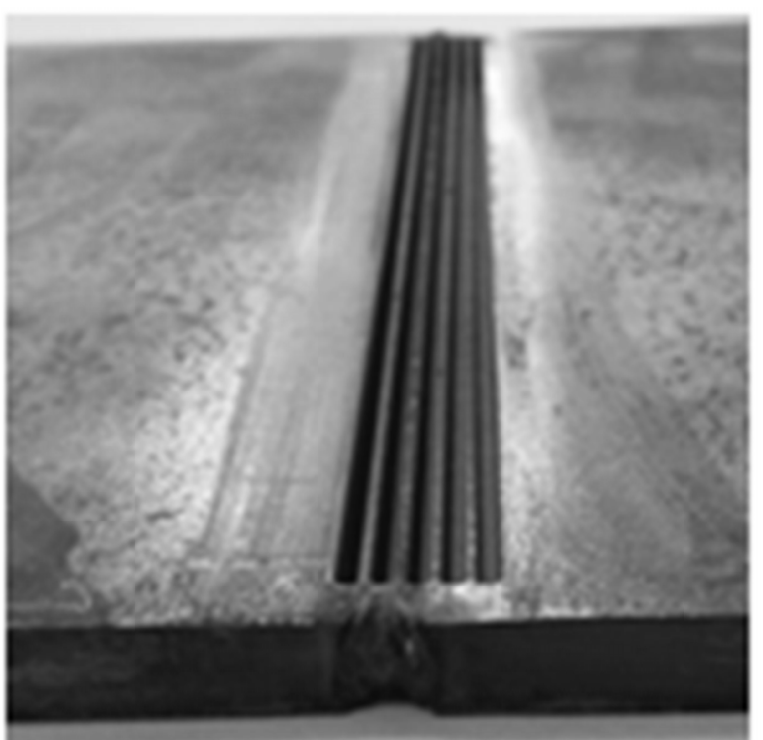

b)

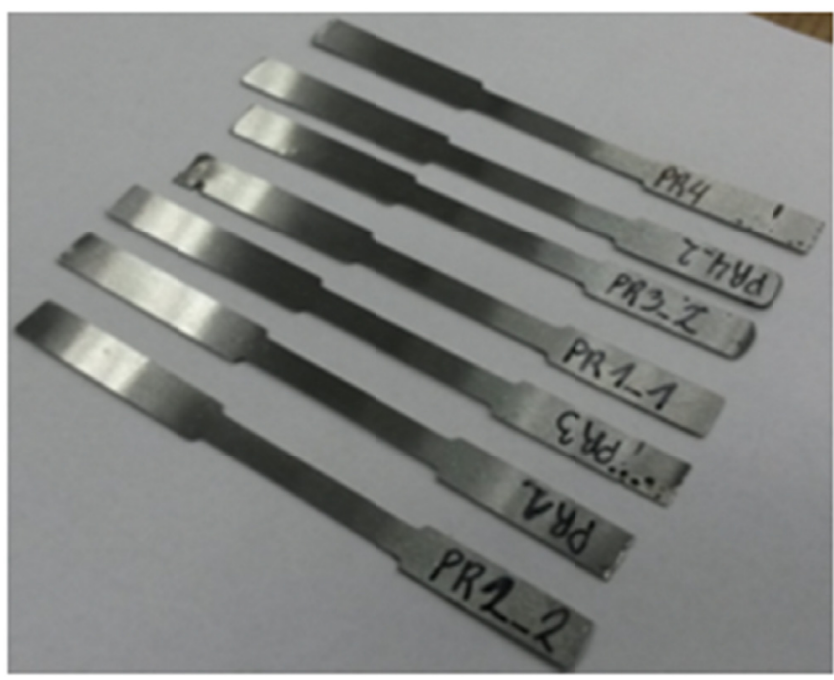

Fig. 2. a) cutting slits made of the Water-Jet A.P.W2010BB machine tool; b) specimens prepared to the uniaxial tensile test 
a)

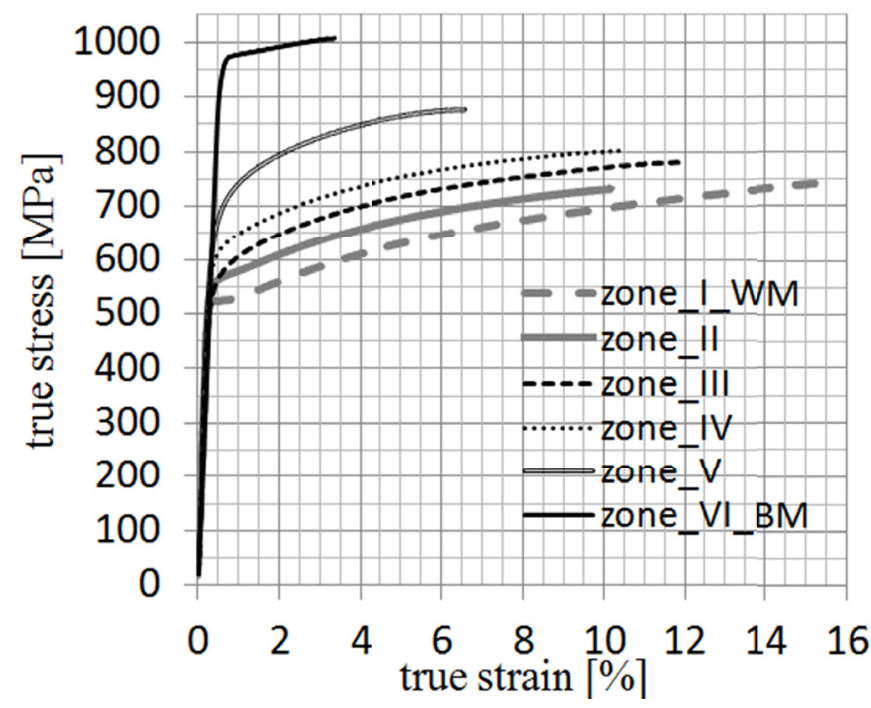

b)

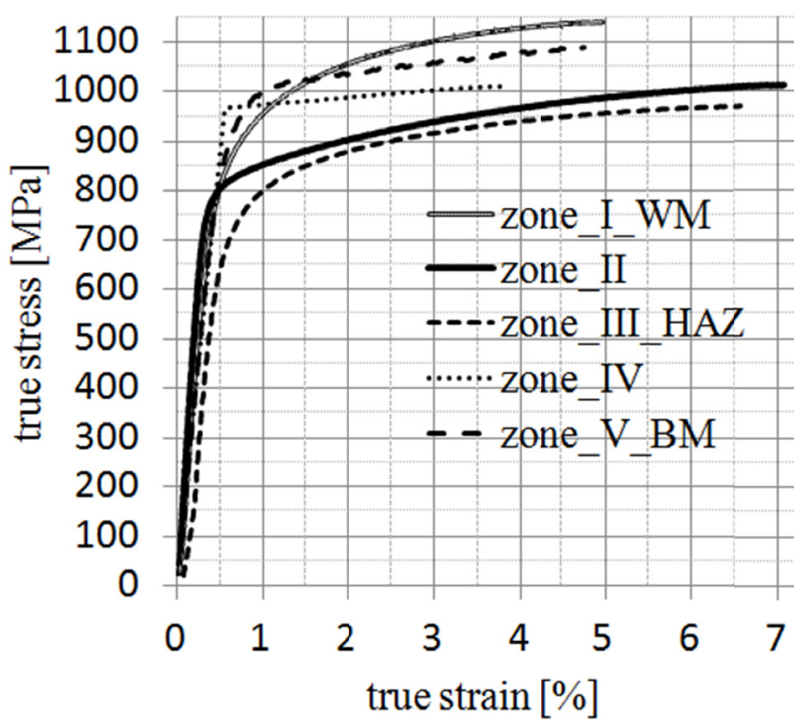

Fig. 3. True plots stress-strain of different zones of welded joints by means of ELS a) $1.2 \mathrm{~kJ} / \mathrm{mm}$ and b) $0.7 \mathrm{~kJ} / \mathrm{mm}$

\section{Determination of strain and stress distributions in welded joints}

In the next stage of research testing was carried out experimental uniaxial tension test of welded joints with using an optical video-system Aramis. By using the video-system obtained the map of strain fields in a welded joint and next exported the strain values along the measurement lines located in the middle part of specimen thickness. Also was carried out measurement of the total displacement of the working part of the specimen during the uniaxial tensile test. This value was introduced as an input parameter to numerical computations.

Numerical calculations were carried out on simplified models, which presented $1 / 2$ of the tested welded joint. An example a modeled specimen is shown in (Fig. 4a). Schematically drawn the line, along which were exported the results of strains. For the created of the numerical model of the joint made of LWE of $1.2 \mathrm{~kJ} / \mathrm{mm}$ declared six zones, the location of which is shown in (Fig. 4b). In joints made of LWE $0.7 \mathrm{~kJ} / \mathrm{mm}$ declared five of the zones (Fig. 4c). Particular zones assigned relevant material properties, determined by means of true stress-strain curves, which were presented above in the (Fig. 3a,b).

In the numerical models loading generated giving appropriate displacement value. The level of displacement was chosen so as to obtain displacement recorded in the experiment by means of video-system Aramis. The obtained results of numerical calculated strains read along the line located in the cross- section of the joint, in the middle part of specimen thickness, what corresponded to the place from which the strain results were exported, obtained by means of video-system Aramis.

a)

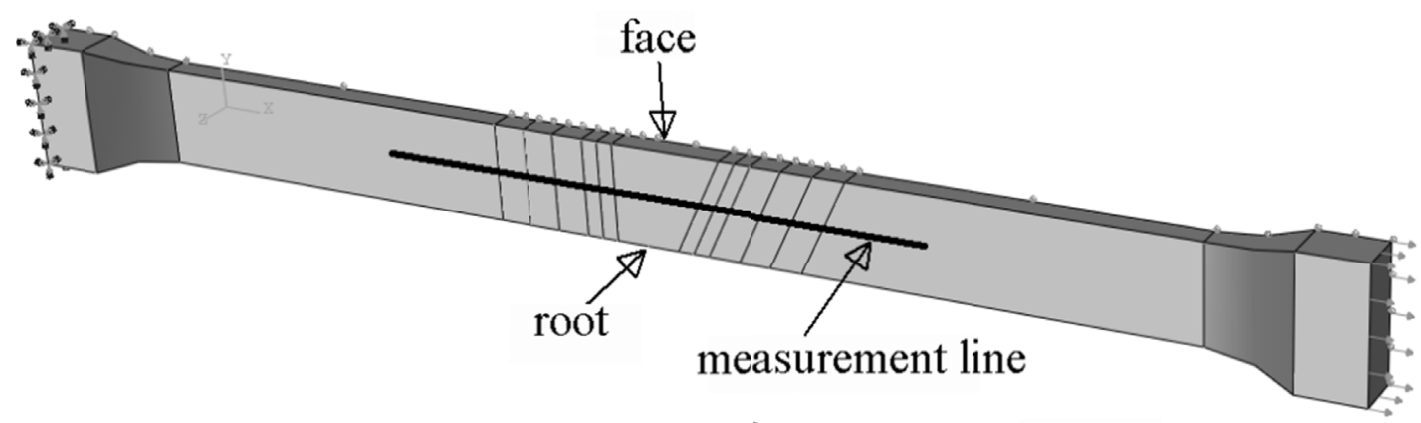

b)

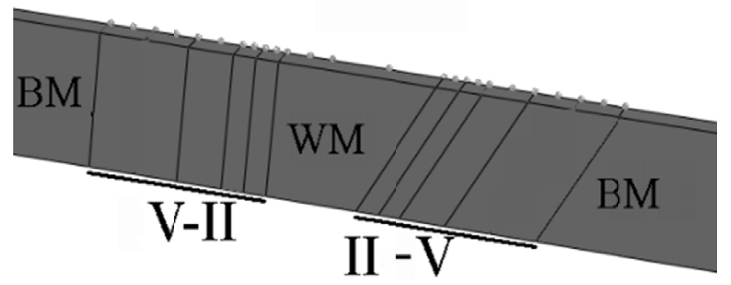

c)

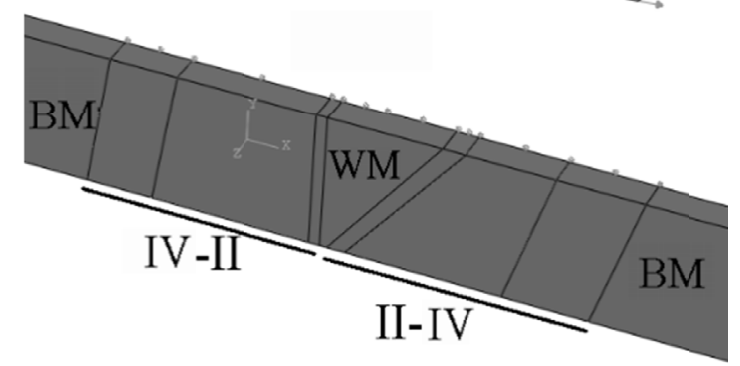

Fig. 4. a) numerical model of joint; and a views of particular zones for the joint made by means of LWE $1.2 \mathrm{~kJ} / \mathrm{mm}(\mathrm{b})$ and $0.7 \mathrm{~kJ} / \mathrm{mm}(\mathrm{c})$ 


\section{Results of FEM calculations}

The results of numerical calculations obtained using FEM were compared with the results of the measurement obtained on the basis of video-system Aramis. Tensile curves of the tested joints made by means of $\mathrm{LWE}=1.2 \mathrm{~kJ} / \mathrm{mm}$ and $\mathrm{LWE}=$ $0.7 \mathrm{~kJ} / \mathrm{mm}$ presented respectively in (Fig. 5a,b). On this curves marked stages in which carried out measurement of strains and stresses presented below in Figures 8 and 9. For presentation were chosen two characteristic moments - of plastification of specimens and achievement of maximum tensile strength value by joints. Exemplary strain results were also read in two next mediate stages.

In Figures $6 \mathrm{a}$ and $7 \mathrm{a}$ presented strain fields obtained by means of FEM for joints made with LWE of $1.2 \mathrm{~kJ} / \mathrm{mm}$ and $0.7 \mathrm{~kJ} / \mathrm{mm}$, respectively. In Figures $6 \mathrm{~b}$ and $7 \mathrm{~b}$ are shown corresponding maps of strain fields obtained on the specimens of welded joints by means of Aramis video-system for the moment

a)

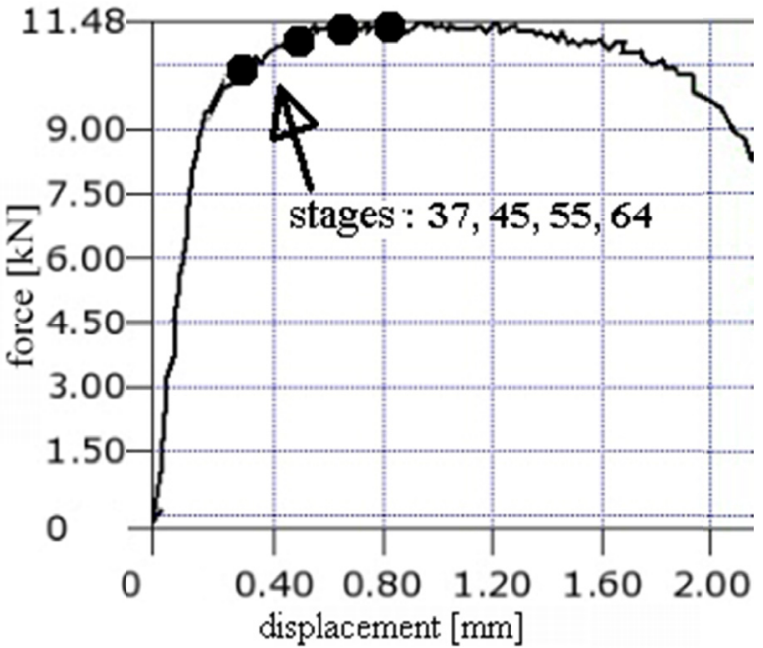

of maximum level strength by joints: for stage 64 ( $\mathrm{LWE}=1.2$ $\mathrm{kJ} / \mathrm{mm})$ and stage $76(\mathrm{LWE}=0.7 \mathrm{~kJ} / \mathrm{mm})$.

In (Fig. 8a,b) are shown the results of strain in the form of graphs obtained respectively along the lines of measurement located in the central part of the thickness of joints for the specified load stages. On the presented graphs introduced background for indicate the range of areas in the joints. Notes WM, HAZ, BM mean the areas in which occurs weld material, areas of heat affected zone and base material. Smooth-lines graphs correspond to strains obtained using FEM, while the graphs with symbols presents strains obtained using by Aramis video-system. In case of welded joint $(\mathrm{LWE}=1.2 \mathrm{~kJ} / \mathrm{mm}$ ) the greatest strains obtained in weld material (Fig. 8a and Fig. 6a,b). With increasing distance from the weld axis, strains gradually decrease to minimum level in the base material. On the graphs one can notice that the results of strains obtained using Aramis system well consent with the results calculated using FEM, however slightly bigger maximum strain levels shown for numerical calculations results.

b)

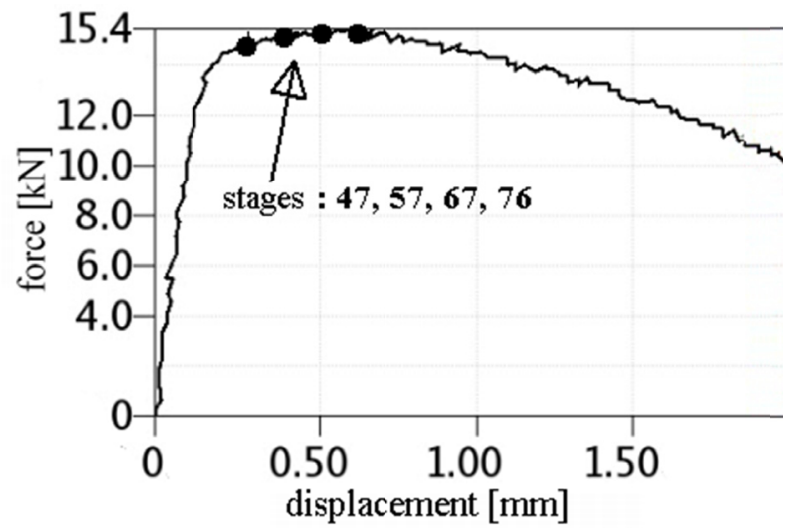

Fig. 5. Tensile curves with marked stages of strains measurement for the joint made of LWE: a) $1.2 \mathrm{~kJ} / \mathrm{mm}$; b) $0.7 \mathrm{~kJ} / \mathrm{mm}$

a)

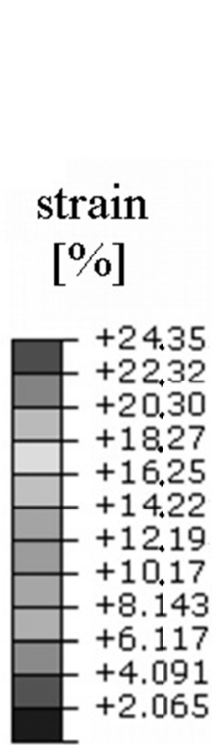

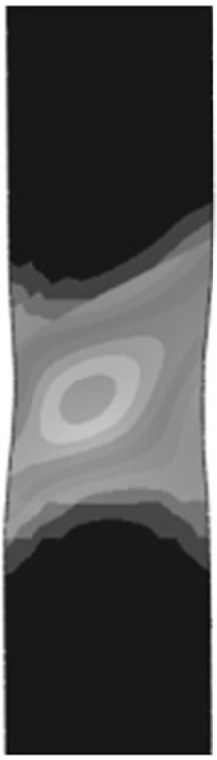

b)

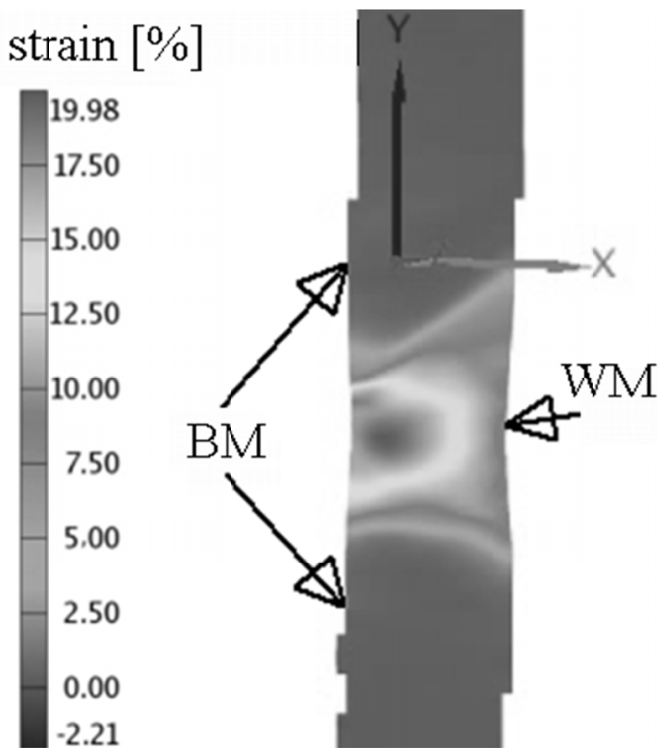

Fig. 6. Strain fields for the joint made by of $L W E=1.2 \mathrm{~kJ} / \mathrm{mm}$ obtained numerically( a) and by Aramis system(b 
a)

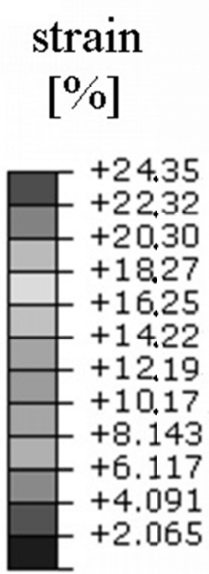

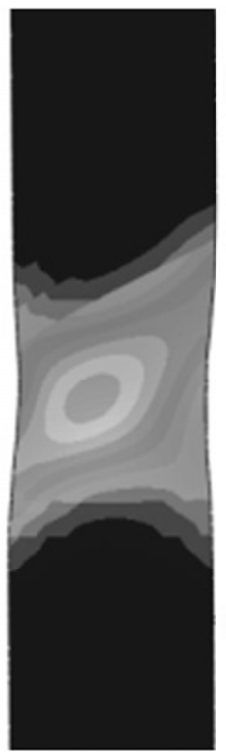

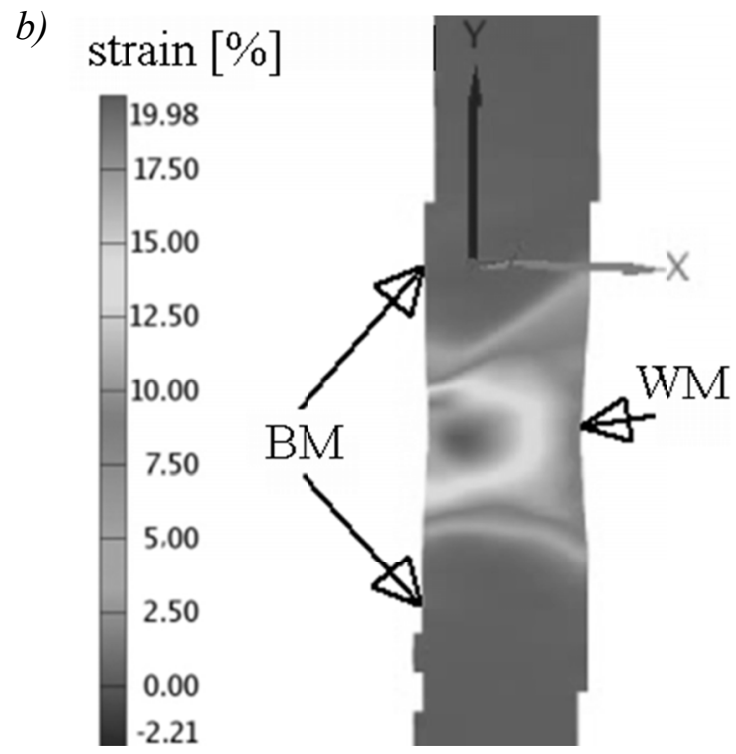

Fig. 7. Strain fields for the joint made by of $\mathrm{LWE}=0.7 \mathrm{~kJ} / \mathrm{mm}$ obtained numerically (a) and by Aramis system (b)

a)

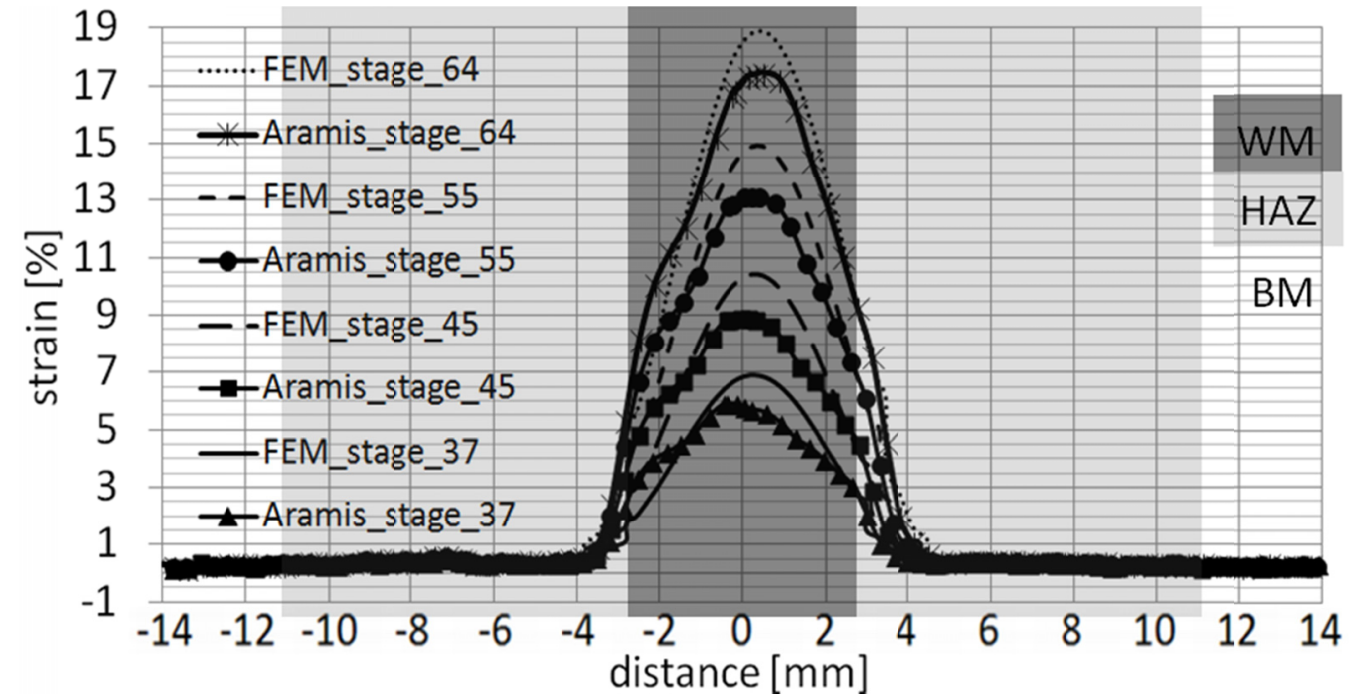

b)

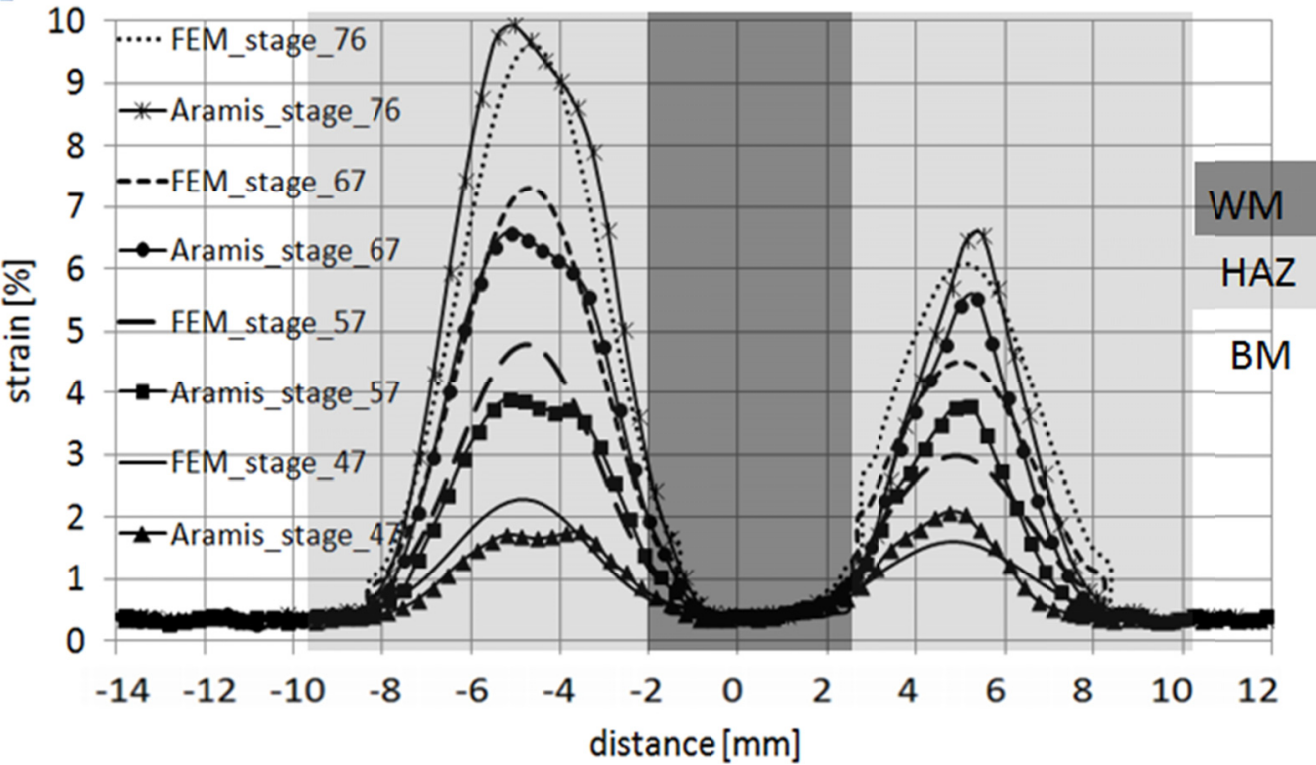

Fig. 8. Strains distribution along the measurement line for the corresponds stages of load for welded joints: a) $L W E=1.2 \mathrm{~kJ} / \mathrm{mm}$; b) $L W E=0.7$ $\mathrm{kJ} / \mathrm{mm}$ 
a)

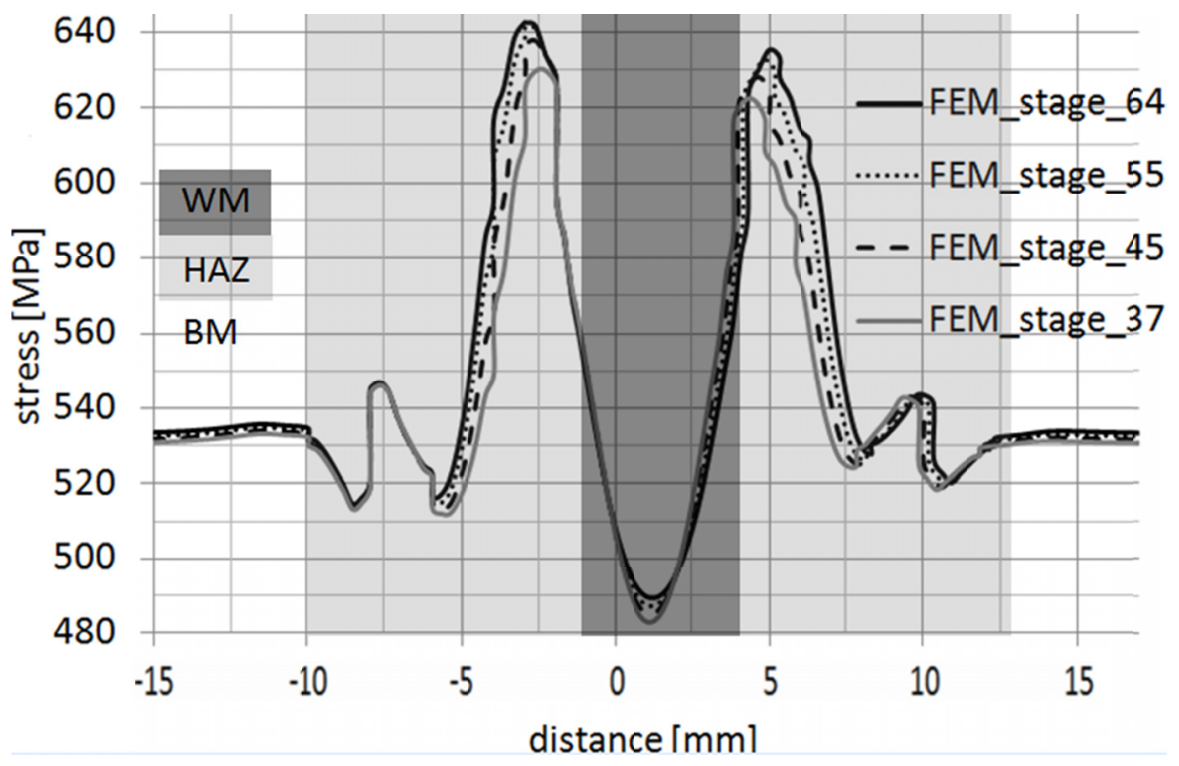

b)

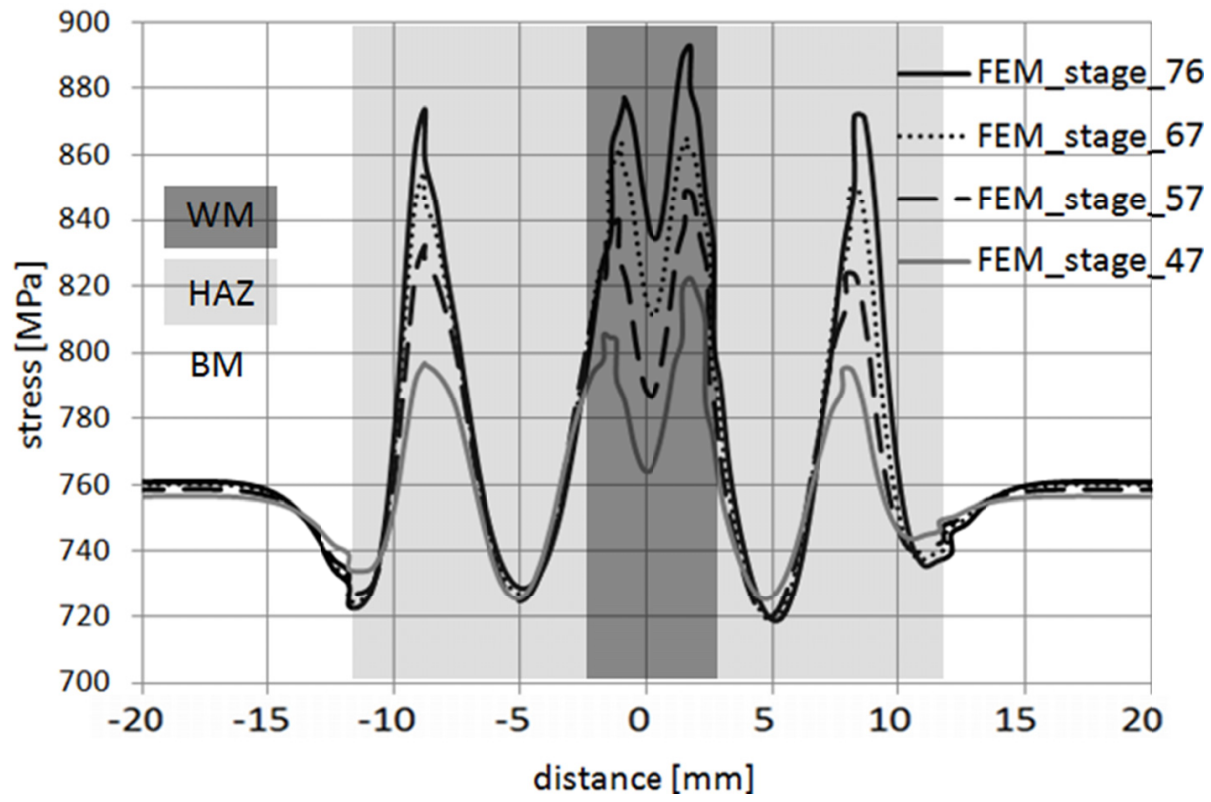

Fig. 9. Stresses distribution along the measurement line for the corresponds stages of load for welded joints: a) $L W E=1.2 \mathrm{~kJ} / \mathrm{mm}$; $b$ ) $L W E=$ $0.7 \mathrm{~kJ} / \mathrm{mm}$

The highest level of strains for the welded joint of LWE $=0.7$ $\mathrm{kJ} / \mathrm{mm}$ occurs in the material of heat affected zone (Fig. $8 \mathrm{~b}$ and Fig. 7a,b). Increasing of the load lead to gradual increase of strains in the heat affected zone on right and on left side of the weld. Comparing the level of maximum strains one can notes that those strain calculated using FEM are higher than the strains obtained by Aramis system. For this welded joint the weld material and base material are the areas in the joint of low levels of strains.

According data presented in the graphs of stress distribution (Fig. 9a) along the measurement line for the welded joint with $\mathrm{LWE}=1.2 \mathrm{~kJ} / \mathrm{mm}$ and stress fields presented at the moment of maximum force (Fig. 10a) may be observed that in the weld material occurs lowest level of the stresses. With increase distance from the weld axis, stress level increases and reached the maximum in HAZ, next the stress level decrease to level characteristic for base material.
For the welded joint made with $\mathrm{LWE}=0.7 \mathrm{~kJ} / \mathrm{mm}$ the highest level of stress distribution received in the weld material. The maximum occur in two areas direct at fusion line (Fig. 9b and Fig. 10b). The stress distribution observed in HAZ material has non-regular character. With increasing distance from weld axis stress levels primary decrease and reached the minimum values of stress distribution, then we observe significant increase and subsequent decrease of stress values to level occurring in base material. (Fig. 9b and Fig. 10b).

\section{Conclusion}

The study shows that on strength of welded joints in which the base material is high-strength tempered martensite steel S960-QC significant influence has the level of linear weld- 
a)

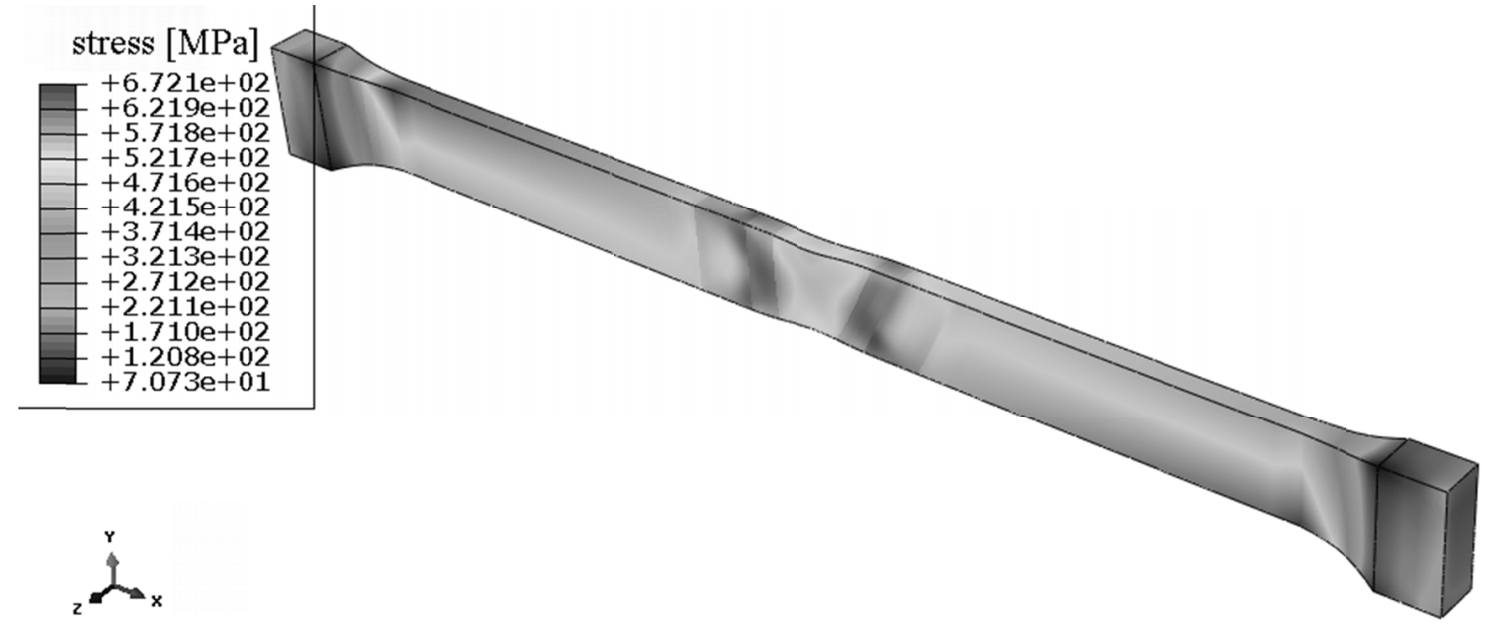

b)

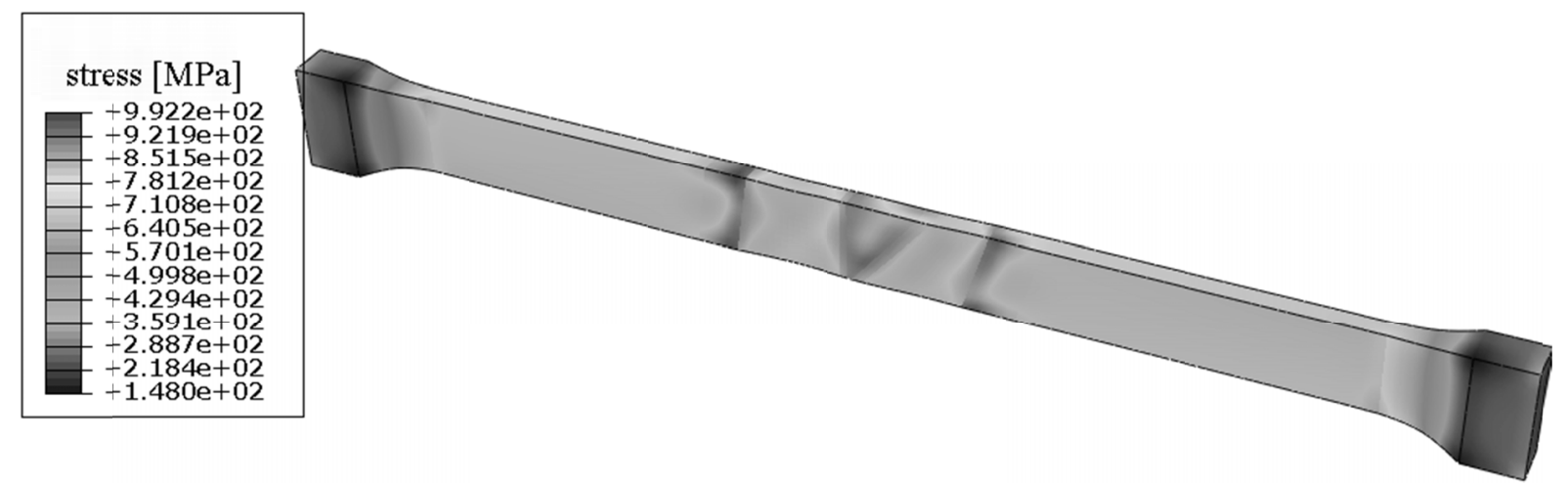

Fig. 10. Stress fields obtained by FEM for the joint made of LWE a) $1.2 \mathrm{~kJ} / \mathrm{mm}$ and b) $0.7 \mathrm{~kJ} / \mathrm{mm}$

ing energy that was used. The joint with $\mathrm{LWE}=1.2 \mathrm{~kJ} / \mathrm{mm}$ is characterized by lower hardness in the weld material (Fig. 1a) and lower strength characteristics (Fig. 3a) in comparison to the base material, S960-QC steel. This is reflected in strain and stress fields forming in the welded joint. The highest level of strain and lowermost level of stress obtained in welded material of this welded joint. Its mean that strength of welded joint are determine the weld material. For welded joints made with $\mathrm{LWE}=1.2 \mathrm{~kJ} / \mathrm{mm}$ the area of lowermost hardness and strength properties are some zones of HAZ material. In these zones would expect initiation of destruction this welded joints.

For welded joints made with $\mathrm{LWE}=0.7 \mathrm{~kJ} / \mathrm{mm}$ the area of lowermost hardness and strength properties are some zones of $\mathrm{HAZ}$ material. In these zones would expect initiation of destruction this welded joints.

Low LWE lasers have been used to make welding joints where the properties of the weld material and HAZ material are at a higher level than WM [8].

The data strain distributions obtained by video-system Aramis and calculated numerically shown a good agreement.

\section{REFERENCES}

[1] D. Porter, Developments in hot-rolled high strength structural steel, Nordic welding conference 06, Finland (2006).

[2] J. Górka, Microstructure and properties of the high-temperature (HAZ) of thermo-mechanically treated S700MC high-yield-strength steel, Materials and technology 4, 617-621 (2016).

[3] I. Dzioba, T. Pała, I. Valkonen, Acta Mechanica et Automatica 7, 4, 64-65 (2013).

[4] A. Gruszczyk, S. Griner, Welded Review 5-6, 39-41 (2006).

[5] I. Dzioba, T. Pała, Logistics 6, 3458-3464 (2014).

[6] E. Tasak, A. Ziewiec, Welded Review 11, 7-12 (2006).

[7] I. Dzioba, T. Pała, K. Mulczyk, Distributions of hardness in laser welded joints of high-strength ferritic steel S960-QC, VIII Scientific and Technical Conference- Terotechnology 2013, Kielce 26-27.09.2013.

[8] T. Pała, I. Dzioba, Experimental-numerical analysis of strength of laser welded joints of S960QC steel, Energetyka 11, 697-699 (2016).

\section{Acknowledgments}

The work was performed as part of research projects MNiSW 01.0.08.00/ 2.01.01.02.0008 and 01.0.08.00/2.01.01.02.0048. 